\title{
Prevalence of Pediatrics Metabolic Syndrome (PMS) Amongst Children in the Age Group of 6-18 Years Belonging to High Income Group Residing in National Capital Territory (NCT) of Delhi
}

\author{
Umesh Kapil • Supreet Kaur
}

Received: 13 January 2010 /Accepted: 24 February 2010 /Published online: 8 September 2010

(C) Dr. K C Chaudhuri Foundation 2010

Sir,

We would like to share findings on prevalence of pediatrics metabolic syndrome (PMS) amongst children in the age group of 6-18 yrs belonging to high income group residing in national capital territory (NCT) of Delhi with the readers of the Indian Journal of Pediatrics.

The studies conducted in developed countries have reported the overall prevalence of PMS as $6.4 \%, 3.1 \%$, $12.7 \%$ utilizing the criteria of hypertension, impaired fasting glucose, Hypertriglyceridemia, abnormal high density lipoprotein (HDL) and central obesity as measured by waist circumference [1-3].

Here it is reported here the prevalence of PMS in 1,331 children belonging to high income group. This data is a part of a larger study published earlier [4].

The children were selected by population proportion to size (PPS) sampling methodology from a list of all public schools with the fees of Rs. 1,000 and above per month in NCT of Delhi. The measurement of blood pressure, serum triglyceride, serum HDL, fasting blood glucose levels and waist circumference was conducted by utilizing the standard methods [5].

The authors considered the presence of PMS when three or more of following risk factors were present in a child. The cut-off for presence risk factors were hypertension (systolic or diastolic blood pressure $\geq 95$ th percentile for age and sex) [6], impaired fasting glucose (fasting blood

\section{U. Kapil $(\triangle) \cdot$ S. Kaur}

Department of Gastroenterology and Human Nutrition Unit,

All India Institute of Medical Sciences,

Ansari Nagar, New Delhi 110 029, India

e-mail: umeshkapil@gmail.com glucose level of $100 \mathrm{mg} / \mathrm{dl}$ and more), hypertriglyceridemia $(150 \mathrm{mg} / \mathrm{dl}$ and more), abnormal HDL $(<40 \mathrm{mg} / \mathrm{dl})$, and central obesity as measured by waist circumference ( $\geq 90$ th percentile for age and sex) [7].

The authors have found the prevalence of PMS as 6.5\% (males $6.9 \%$ and females $5.9 \%$ ). The PMS is known to a pre-cursor of adult metabolic syndrome in a population. The findings of the present study indicate that PMS is significant but hidden public health problem, which requires urgent attention of the programme managers and administrators in the health sector.

\section{References}

1. Duncan GE, Li SM, Chou XH. Prevalence and trends of a metabolic syndrome phenotype amongst US adolescents, 19992000. Diab Care. 2004;27:2438-43.

2. Riatakari OT, Porkka KV, Viikari JS, Ronnemma T, Akerblom HK. Clustering risk factors for coronary heart disease in children and adolescents. The cardiovascular risk in young Finns study. Acta Pediatr. 1994;83:935-40.

3. de Ferranti SD, Gauvreau K, Ludwig DS, Neufeld EJ, Newburger JW, Rifai N. Prevalence of the metabolic syndrome in American adolescents. Circulation. 2004;110:2494-7.

4. Kaur S, Sachdev HPS, Dwivedi SN, Lakshmy R, Kapil U. Prevalence of overweight and obesity amongst school children in Delhi, India. Asia Pac J Clin Nutr. 2008;17:592-6.

5. WHO: Physical Status: The use and Interpretation of Anthropometry. Report of a WHO Expert Committee. World Health Organisation Technical Report Series 854. Geneva: WHO; 1995. p. 427-30.

6. Update on the 1987 Task Force report on high blood pressure in children and adolescents. Working group report from the National High Blood Pressure Education Program. Pediatrics 1996;98:649-58.

7. Zimmet P, Alberte G, Kaufman F. The metabolic syndrome in children and adolescent. Lancet. 2007;369:2059-61. 